\title{
China and Asia-Pacific security building in the new century
}

\author{
Zhu Majie
}

Since the end of the Cold War, great attention has been focused on building up a new Asia-Pacific security mechanism. Many countries in the region have been taking an active part in this process. Security dialogues have been carried on in varied forms at different levels. The main purpose of such kinds of activities is to seek to shape a new multilateral security framework for the Asia-Pacific region, in which all the countries in the region will be equally involved in dealing with issues of common interest. Challenges and opportunities co-exist for the Asia-Pacific security building. So long as the nations concerned continue their constructive efforts, the Asia-Pacific region will become more secure in the new century.

\section{Challenges for Asia-Pacific security}

Ushering in the new century, the Asia-Pacific countries are facing a host of security challenges. Besides transnational crimes, drug trafficking, environmental damage and the proliferation of weapons of mass destruction, there are some potential disputes and conflicts, such as the confrontation between North Korea and South Korea, tension across the Taiwan Strait, territorial disputes over the islands in the South China Sea, as well as disputes over the northern islands between Japan and Russia. All these potential crises may pose threats to the stability and security of the region. It is also worrisome that some countries have been enhancing their military capabilities, sharply increasing their defence expenditure.

Among the potential crises, there are three major issues: the Korean issue, the Taiwan issue, and the Nansha Islands disputes. The Korean issue is closely related to significant security interests of the two Koreas, as well as of the concerned major powers of the Asia-Pacific region. The Taiwan issue is part of China's internal affairs. But US interference has made it ever more difficult, giving its political support to the separatist forces in the island, constantly supplying arms to 
Taiwan, sometimes even flaunting its military forces in the Taiwan Strait. Following the United States, Japan is also involving itself in the Taiwan issue. So any conflict resulting from the issue would greatly impact on the relations among China, the United States and Japan, as well as on the stability and security of the Asia-Pacific region. The Nansha Islands issue involves the territorial sovereignty and marine rights of China, Vietnam, Malaysia and the Philippines. This is a historical issue which has significant political, economic and strategic consequences for the countries concerned. At present it is very difficult to find a resolution satisfying the requirements of the concerned parties. Besides, the involvement of some other big powers has made the issue increasingly complicated. Therefore, any improper handling of the issue could cause crises that would have great impact on the stability and security in the Asia-Pacific region.

The armaments build-up of some Asia-Pacific countries has caused great concern in the region. In spite of its economic deterioration, Japan's defence expenditure has been increasing since 1991. Its defence budget in 2000 was several times the total sum of that of all the ASEAN countries. In the fiscal year of 2000 , US defence expenditure reached US $\$ 288.8$ billion, which was about twice the total sum of that of China, Japan, France, Britain and Russia. Moreover, the United States has no intention of reducing its military deployment in the Asia-Pacific region. On the contrary, it has continuously improved the quality of its armaments. People have noted that while the Asia-Pacific region continued to be burdened with the residual manifestations of the Cold War, there were new tensions that had implications for regional security. These included:

- the signing of the Visiting Forces Agreement between the United States and the Philippines;

- the signing of the New Guidelines for the US-Japan alliance that gives Japan a bigger role in regional security and increases its cooperation with the United States;

- the proposed Taiwan Security Enhancement Act and the US administration's decision to sell a huge amount of advantageous weapons coupled with the United States' desire to introduce the Theatre Missile Defence (TMD) system to Taiwan;

- the new changes of US policy towards North Korea that enmeshes the Korean peninsula in a new plight;

- the potential attack of speculative capital which still poses a threat to the economic security of the countries in the region under the mega-trend of economic globalization and free capital flow.

\section{Three patterns of security building}

To address these challenges, nations in the Asia-Pacific region are in great need of enhancing mutual understanding and trust and of seeking consensus on a series of problems. There are three major ways of security cooperation in the region. 
First, bilateral military alliances. Such security arrangements stress security building by military means in order to deal with their real or potential enemies. In the post-Cold War era, the United States has been making efforts to strengthen military coalitions with its allies, such as Japan, South Korea, Australia, Thailand and the Philippines. The United States claims that its treaty alliances with these countries, and its commitment to keeping approximately 100,000 US military personnel in the region, serve as the foundation for America's continuing security role. In 1996, the United States and Japan reaffirmed that their bilateral security relationship 'remains the comerstone for achieving common security objectives and for maintaining a stable and prosperous environment for the Asia-Pacific region.' In recent years, the US has been actively carrying on the programs of TMD and National Missile Defence (NMD), and trying to introduce TMD into the region. Some of its allies have shown their support for the programs: they consider such bilateral military alliances the basic security measure for the United States and its allies in addressing security challenges.

Second, cooperation on the basis of mutual trust and confidence. In recent years, China, Russia and three Central Asian countries (Kazakhstan, Kyrghystan and Tadzhikistan) have been making great efforts to improve their relations. Several agreements were signed on confidence building and mutual reduction of military forces in the border areas. In June, 2001, the Shanghai Co-operation Organization (SCO) was set up on the basis of the 'Shanghai Five' (China, Russia, Kazakhstan, Kyrghystan, Tadzhikistan) with Uzbekistan as its new member. The $\mathrm{SCO}$ is a new regional body to promote peace, stability and economic ties. Each member nation should regard 'maintaining regional security' as the top aim of the group, carry forward 'the spirit of unity' to solve problems through friendly consultation, adhere to the principle of 'being open', meaning it is not aligned and does not target any particular country, adhere to the principle of the UN Charter, and push for a democratic and fair political and economic order in the world. Establishing this co-operation mechanism has historical significance, which shows 'the Shanghai Spirit', advocating mutual trust and benefit, equality, consultation and respect for different civilizations and the pursuit of common development. The SCO will doubtless contribute to maintaining regional security and stability, as well as world peace and development.

Third, regional security dialogues. The Association of South East Asian Nations (ASEAN) has played an important role in promoting security dialogues not only among the member nations in the organization but also among all nations in the Asia-Pacific region. In recent years, ASEAN has expanded its role in initiating the ASEAN Regional Forum (ARF) on the full range of common security challenges. The major powers including the United States, China, Japan, Russia and the European Union were invited to attend the ASEAN Regional Forum. The security dialogues under ARF have offered opportunities for the concerned parties to discuss different security concepts, models and mechanisms, seeking for substantial cooperation, and for configuring a multilateral security framework, in 
which all the Asia-Pacific nations will be involved on an equal footing. The goal of the participants in the forum is to reach consensus on building up confidence mechanisms, pursuing preventive diplomacy and strengthening strategic meetings on dispelling conflicts. The facts have shown that such dialogues as those under the ARF are of great benefit to enhancing regional security.

The three models already mentioned fall into two categories. The first type gives priority to military means in bilateral and regional security. This is the continuation of the old security configuration of the Cold War era, while the second type lays stress on multilateral security by non-military means, which is more dynamic and promising in the new century.

\section{Seeking consensus on security concepts}

To build up a new security mechanism in the Asia-Pacific region, it is necessary to seek consensus on five aspects.

First, mutual trust is the most important prerequisite for regional security building and arrangements. At present, the level of mutual trust between respective bilateral nations in the region is obviously limited by the different strategic objectives of each nation. Any enforcement and expansion of military alliance will cause suspicion among nations in the region. Considering the historic factors, such types of military alliances may co-exist with some other new security mechanisms so long as the alliance does not pose a threat to other countries. Due to the low level of mutual trust, it is difficult for the nations concerned in the region to forge a sound foundation for substantial security cooperation. Therefore, it is absolutely necessary for. all nations to enhance mutual trust despite their different social systems and cultures.

Second, new concepts of security should be applied. In terms of exploring the possibility of building up a new mechanism for the Asia-Pacific region, attention should be given to concepts of security. In the post-Cold War era, some new security concepts have emerged, such as common security, comprehensive security and multilateral security. With increasing economic interdependence, the common security of the countries in the region meets the need of common interests. No country can or should maintain its own security interests at the expense of other countries' interests. In order to realize common interests, security cooperation must develop among the countries in dealing with various common issues, such as environmental protection, drug trafficking and the proliferation of weapons of mass destruction. The concept of comprehensive security takes full consideration of the overall balance of politics, economy, society, culture and military in handling security problems. It also takes into account the ecological environment. As for the concept of multilateral security, it is not a new one. The Conference on Security and Cooperation in Europe was one of the products of such a concept during the Cold War, but in the post-Cold War era, the concept of multilateral security is quite different in nature from that of the past. It suggests building up a multilateral security regime on the basis of economic cooperation, inviting all the 
concerned parties to participate in the system without exclusiveness, aiming at common development and prosperity. In addition, it advocates equal participation. of the concerned parties so as to restrict the desire of any country for dominance or leadership.

Third, new security norms should be formulated for all the concerned nations in the region to observe. This is a very important point. Many people maintain that the norms for security relations should be a new type of mutual benefit, mutual respect, and equal consultation in the process of regional security cooperation. In order to set up security norms which can be accepted and observed by all nations in the region, it is obvious that only by seeking common ground on major issues while reserving differences on minor ones can a new set of norms be formulated.

Fourth, there is the question of who will be the leading actor on the stage of security cooperation. The United States holds that 'America has an unparalleled record of international leadership' and 'the need for American leadership remains as strong as ever'. Although the United States has the ambition to play its role of leadership in the regional security arrangement, the other nations also try to play their own role in maintaining stability and in the regional security arrangement, no matter how effectively each nation can function in this regime.

Fifth, pragmatic actions should be further taken to create better conditions for shaping the security mechanism in the Asia-Pacific. Since the Korean issue is very important for establishing a security system in the region, all the nations concerned should continue their support for the peace process on the inter-Korean peninsula. Meanwhile, it will be a good beginning to take the 'four-party talks' as a basis for a subregional security mechanism. The intention of the 'four-party talks' is to build a permanent peace mechanism on the peninsula. During the third round of talks in 1998, the four sides agreed to establish two working groups to deal with 'tension-reduction' and a 'peace mechanism'. As a first step, the participants should conclude a peace agreement to replace the truce regime set up at the end of the Korean War. On this basis, all the concerned parties should take further measures to reduce the deployment of troops and weaponty along the demilitarized zone. These actions will help reduce tensions on the peninsula and pave the way for building up a new peace mechanism. In the long term, the new security regime in Northeast Asia should not exclude Russia and Japan if such a regime is to effectively play its role in maintaining a stable and peaceful environment in the region. In the future, when there are conditions for establishing a certain kind of security organization, for instance, an 'Asia-Pacific Security Conference', the countries in the region will enjoy a much more peaceful and stable environment for their economic and social development.

To sum up, Asia-Pacific countries should work together to set up a new security concept with mutual trust, mutual benefit, equality and collaboration at its core and strive to create a peaceful international environment of long-term stability and security. 


\section{China as a factor in Asia-Pacific security building}

The rise of China is a stabilizer not only for the Asia-Pacific region but also for the whole world. The remarkable economic progress achieved by China in the last two decades is an important contribution to the stability of the region. In the process of its modernization, China is actively integrating itself into the world community. Its security strategy in the region mainly focuses on the following objectives:

- To safeguard national unity and territorial integrity;

- To maintain a stable and peaceful international environment in its periphery; and

- To establish good relations with its neighbouring countries.

In light of these strategic objectives, China has been doing its best to guarantee the national security, to maintain the regional stability and security, and to promote the building-up of Asia-Pacific security mechanisms. China has dealt with its territorial disputes with the concerned countries as well as security building in the region in a positive way. In order to maintain a stable and peaceful environment, China has made the proposal of setting apart the disputes and has been engaged in bilateral negotiations with parties concerned,with a view to jointly benefiting from the area. China also stands for mutual reconciliation through friendly consultation. Before reaching resolutions to the problems, the status quo of the disputed areas should be maintained so as to create a peaceful and stable environment for nations concerned.

With the changes taking place in the world, China has readjusted its policy towards security arrangements, taking an active part in various regional and global security activities to sustain a more secure environment.

First, China gives priority to improving bilateral relations with the United States. At the same time, great attention has been paid to advancing Sino-Japan relations. China has been trying its best to resolve the problems in SinouS relations as well as in Sino-Japan relations through dialogues and consultations. As we know, any severe conflict between any two powers will pose a great threat to the stability and security of the region. The United States, Japan and China are all major nations, and have an obligation to maintain regional security. It has been suggested that a trilateral security arrangement between the United States, China and Japan will be more conducive to the Asia-Pacific region. This idea is worth considering and feasible if the three nations could begin with regular ministerial meetings. Before making a trilateral security arrangement, a constructive strategic partnership between China and the US or between China and Japan will create better conditions for the improvement of trilateral relations. Such a relationship will be a big step towards the configuration of peace and security in Asia-Pacific.

Second, China shares the efforts in building up a subregional security mechanism in Northeast Asia. In order to reduce tension on the Korean peninsula, China has been trying its best to help create conditions for a peaceful resolution of the Korean issue by developing contacts with the United States, South Korea and 
North Korea. China has also made efforts in promoting productive dialogues as well as in the process of 'four-party peace talks' among the United States, China and the two Koreas. In so doing, China hopes to help shape a sub-regional security mechanism through consultations, so that the peaceful reunification of Korea can eventually be realized, which will have a far-reaching positive impact on security building in Northeast Asia as well as in the whole Asia-Pacific region.

Finally, with regard to shaping a regional security mechanism, China's involvement has become more and more active even if it is known very well that this is not an easy undertaking. In order to increase mutual understanding and trust, regional dialogues initiated by ASEAN have taken place in recent years. China has been taking an active part in the ARF, which helps dispel suspicions and seeks for more common ground for security cooperation. In term of configuring some binding security regime, China hopes that some kind of security mechanism will be established in order to ensure regional political stability and economic development. There are five principles for such a mechanism:

- The mechanism must be based on the Five Peaceful Co-existence Principles, and no country should seek regional hegemony;

- Disputes between countries must be solved peacefully, and if an immediate solution is not available, relevant disputes could be shelved and normal exchanges between countries should be maintained;

- Armament must be maintained at the level that is necessary for a country's proper defence;

- All the nuclear powers must take the obligation of not using nuclear weapons first and not using or threatening to use nuclear weapons against non-nuclear countries; and

- Cooperation in economic, trading, scientific and technological fields must be enhanced, and the developed countries should help the developing countries.

In handling its domestic affairs, China gives first priority to its stability in order to continue the momentum of its economic and social development. It also takes full consideration of regional stability and peace while upholding the principle of national unity and territorial integrity. Take the Taiwan issue as an example. It is well known that Taiwan is an inseparable part of China, and of course, the Taiwan issue is one of China's internal affairs. This issue has become very complicated and difficult. That is because, on the one hand, there is foreign intervention, and on the other hand, there is the increasing trend towards Taiwan's independence by the separatists under the US security umbrella. Since 1979, the United States has tried to use the Taiwan Relations Act (TRA) to justify its security relations with Taiwan. In recent years, the United States has also enlarged its arms sales to Taiwan. It even agreed to provide Taiwan with AIM-120 advanced medium-range air to air missiles in April 2000. Besides, the United States has decided to sell some other types of advanced weapons to Taiwan, such as long range radar system, air to 
ground missiles coupled with the desire to introduce TMD. In March 1999, Senator Jesse Helms introduced the 'Taiwan Security Enhancement Act' (TSEA) to the Committee on Foreign Relations of US Senate. If the proposed TSEA comes into law, the relations between the United States and Taiwan will become a de facto military alliance, which will seriously violate the basic principle of international law and arbitrarily infringe on China's sovereignty. Therefore, China has strongly opposed US attempts to make the proposed TSEA come into effect. Considering the special circumstances of the Taiwan issue and the fundamental interests of the whole nation, China has insisted on its resolution of reunification by peaceful means. Its final objective is to reunify Taiwan with the mainland in the formula of 'one country, two systems'. In order to realize the goal of reunification, the Chinese government is ready to show greater flexibility in its efforts to settle the Taiwan issue. According to the explanation of Wang Daohan, Chairman of Association for Relations Across the Taiwan Strait (ARATS), the one China principle means: 'There is only one China in the world. Taiwan is part of China, which is not yet unified at the moment. The two sides should make joint efforts under the one China principle, to hold consultations on an equal footing and discuss national reunification together. A nation's sovereignty and territorial integrity are inseparable. Taiwan's political position should be discussed under the precondition of the one China principle'. Under such circumstances, any instigation and encouragement to Taiwanese separatists' ambitions by foreign forces will eventually worsen the situation of the Taiwan Strait, which would also destabilize the Asia-Pacific region. So long as the foreign powers stop their interference in China's internal affairs on the Taiwan issue, the peaceful reunification of the country will definitely become much easier. There is no doubt that the peaceful resolution of the Taiwan issue will contribute to maintaining the stability and peace of the whole region.

What China has done fully shows that China plays an important and positive role in the regional stability and security building. In the new century, "China is committed to regional and world peace' and 'wants to be trustworthy friends of the world people forever'.

\section{Conclusion}

There are plenty of opportunities as well as challenges for shaping a new security mechanism in the Asia-Pacific region. To address the challenges, the nations in the region should work together for a more secure environment, enhancing mutual trust and understanding and seeking consensus on the concepts, norms and rules of security mechanisms. There are different forms of security cooperation. Comparatively speaking, non-military security cooperation is preferable in the post-Cold War era. In future, conditions should be created to establish some security mechanisms for the whole region. The concerned parties should first make further efforts to establish a peace mechanism on the Korean peninsula, then try to set up a security regime for East Asia or Asia, and finally, strive to formulate a 
security mechanism for the entire Asia-Pacific region on the basis of equal participation.

The rise of China is a stabilizer for the security of the Asia-Pacific region and the world at large. China has become increasingly involved in international security affairs. China wants to safeguard its national security, to maintain regional stability and peace, and to promote the building-up of Asia-Pacific security mechanisms. In light of these objectives, China stands for mutual reconciliation through friendly consultation of territorial sovereignty and marine rights. In handling its internal affairs, China also takes full consideration of regional stability and security while upholding the principle of national unity and territorial integrity. What China has done fully shows that China is a trustworthy country in maintaining stability and security in the region as well as in the world. 